\title{
Sendingwetenskap vir die derde millennium - Deel II
}

P G J Meiring

(UP)

\section{ABSTRACT}

Missiology for the third millennium - Part II

This article contains the second part of professor $P G J$ Meiring's inaugural lecture, on accepting the position of Head of the Department of Science of Mission and Science of Religion (Godsdiens- en Sendingwetenskap) at the Theological Faculty, University of Pretoria.

Taking his cue from an imaginary court hearing in Africa (described by Walbert Buhlmann) where the missionary endeavours of the Church in this continent over many years were to be weighed and judged, Meiring devoted the first section of his lecture (published in Skrtf en Kerk 19(2) 1998) to the questions: What are the nature, aims and content of Science of Mission? How does it find its place among the other theological disciplines?

The second part of this lecture, published below, describes the fivefold challenges awaiting students of Science of Mission on the eve of the Third Millennium: the need to identify its theological point of departure; to redefine its relationship to the church; to rediscover its context (in our case, the context of Africa); to decide upon a relevant agenda; and to develop a responsible method.

Only after all this has received proper attention, a knowledgeable judgement on missions - as well as the Science of Missions - may be made.

\section{OP WEG NA DIE DERDE MILLENNIUM: 'N VYFTAL UITDAGINGS}

Die beoefening van die Sending - veral ook van die Sendingwetenskap as vakdissipline - vereis op die vooraand van die Derde Millennium nuwe en kritiese besinning. In Deel I van die artikel (Skrif en Kerk 19(2) 1998) is na aanleiding van ' $n$ fiktiewe verhoor waarin die eeuelange sendingonderneming in Afrika voor die regbank gesleep word, waarvan die Katolieke missioloog Walbert Bühlmann op 'n onderhoudende wyse vertel, 'n aantal wesensvrae aan die orde gestel: Wat is die eie aard, die inhoud en die doel van die Sendingwetenskap? Wat is sy verhouding tot die ander teologiese dissiplines? Verdien die Sendingwetenskap hoegenaamd 'n plek in die teologiese ensiklopedie? 
Maar uiteindelik is hierdie vrae wat in die verlede soveel aandag vereis het, nie die enigstes op die agenda nie. Ook oor sy planne vir die toekoms word die Sendingwetenskap voor die gereg gedaag. Dit is duidelik dat die Sendingwetenskap - as die vak enigsins aanspraak op geloofwaardigheid en relevansie wil maak - in die jare wat kom, aandag aan 'n hele aantal uitdagings sal moet gee. Vyf van die belangrikste uitdagings is die volgende:

\section{1 'n Teologiese uitgangspunt}

Oor die teologiese uitgangspunt, oor die vertrekpunt waaruit Sendingwetenskap in die jare wat kom beoefen behoort te word, word daar die afgelope tyd 'n lewendige debat gevoer. By hierdie debat is onder meer van ons kollegas aan die Universiteit van Suid-Afrika intens betrokke. As die vraag of daar hoegenaamd nog plek vir denominasie-gebonde teologiese fakulteite aan die staatsgesubsidieerde universiteite in 'n Nuwe SuidAfrika met sy reënboogbevolking behoort te wees, brandend geword het, geld dit nog meer die bestaan en die funksionering van Sendingdepartemente. Kobus Krüger, hoof van die Departement Godsdienswetenskap aan UNISA het dit vlymskerp gestel: "Non-Christians had (and still have) the dubious privilege of having their taxes funneled into faculties and departments aimed at converting them from their own religion. This sounds like a sick joke. It is, to put it bluntly, a monopolistic and discriminatory arrangement" 1 .

In aansluiting hierby pleit die missioloog $\mathrm{J} \mathrm{N} \mathrm{J} \mathrm{Kritzinger} \mathrm{in} \mathrm{sy}$ professorale intreerede aan UNISA, vir die vestiging van 'n neutrale Departement van Sendingwetenskap, waar van die gebruik om slegs die sendingaksie van één godsdiens (die Christendom) te bestudeer en te doseer, wegbeweeg sal word, waar die sending van alle godsdienstige gemeenskappe in die land aan die orde gestel word. Christene is nie die enigste wat "sending" beoefen nie; ook Jode, Moslems, Hindoes en Boeddhiste wil graag hul diepste oortuigings met ander deel, wil ander met hul getuienis bereik, wil aan ' $n$ beter en meer regverdige samelewing help bou, wil by die bewaring van die aarde betrokke wees - kortom, hulle het alles wat Christene op hul sendingagenda het, ook op hulle lys geskryf. Die terrein van die Sendingwetenskap is om, sonder om kant te kies, die dinamiese verhouding op die grense van die godsdienstige gemeenskappe te beskryf, om die "osmose" wat plaasvind te bestudeer. "I suggest that missiology should no longer focus exclusively on Christian mission, but widen its focus to include the missions of various religions" 2 .

Met respek het vir die standpunte van kollegas aan ander universiteite - in ons land sowel as in die buiteland - wat die keuse uitgeoefen het 
om teologie interdenominasioneel, selfs intergodsdienstig, te beoefen, is dit nie die weg wat aan die Departement Sendingwetenskap aan die Universiteit van Pretoria gevolg wil word nie. Hierdie departement funksioneer binne 'n Christelike teologiese fakulteit, waar die vak nie anders as op dié wyse te beoefen kan word nie. "Missiology", skryf David Bosch "as a branch of the discipline of Christian theology, is not a disinterested or neutral enterprise; rather, it seeks to look at the world from the perspective of commitment to the Christian faith"3.

Dit beteken nie dat die Sendingwetenskap op 'n arrogante, paternalistiese, diskriminerende wyse beoefen mag word, wat op 'n ongevoelige manier met die diepste oortuigings van ander afreken nie. Dit beteken veral ook nie dat die Sendingwetenskap nie ook die opdrag ontvang het om van tyd tot tyd selfkrities die hand diep in eie boesem te steek nie - dis baie nodig dat dit gebeur. Wat ook waar is, is dat ' $n$ mens kwalik van een finale Christelike sendingteologie kan praat, dat sendingteologieë deur die jare ontwikkel, dat een paradigma na die ander mekaar opvolg, dat ons van tyd tot tyd met sendingteologieë "van bo" en dan weer met sendingteologieë "van onder" - soos Jongeneel en Van Engelen dit beskryf $f^{4}$ - gekonfronteer sal word. Maar van sy geloofsuitgangspunt kan 'n mens die Sendingwetenskap nie wegkry nie. Soos Paulus, die eerste sendeling-teoloog, verklaar ons met die oortuiging van ons lewens, skryf ons onderaan elke paradigma: "Ek verkondig Christus, en Hom as die gekruisigde!" (1 Kor 1:23). Om op pad na die jaar 2000, te midde van al die nuwe omstandighede, die ingewikkelde probleme van die Derde Millennium die hoof te bied, het die Sendingwetenskap 'n duidelike geloofsuitgangspunt nodig. Daarsonder dien ons niemand nie - nie God nie, en ook nie die wêreld waarheen die Here God ons gestuur het nie. Ook nie ons vakwetenskap nie.

In sy poging om hierdie duidelike geloofsuitgangspunt te handhaaf en uit te bou, het die Sendingwetenskap die samewerking en die insigte van die ander teologiese dissiplines dringend nodig. As 'n mens die verhaal van die moderne sendingbeweging die afgelope tweehonderd jaar onder die loep neem, skryf Wilbert Shenk, kom jy tot die pynlike ontdekking dat teoloë oor die algemeen geneig was om die sending te ignoreer. Daardeur het hulle nie net die teologie nie, maar ook die sending oneindig skade berokken. As dit waar is dat die sending die wesenstaak van die kerk is, dat die sending met die mees fundamentele vrae wat bestaan moet worstel, kan sendingwetenskaplikes met reg aanspraak maak op die insette van hul kollegas in die ander dissiplines van die teologiese fakulteit. Vir dié teoloë behoort dit ook nie te moeilik te wees om te weet wat om te doen nie, 
herinner Shenk: "One has only to turn to the New Testament to find the basic model for theology that is missionary, and mission that is theological"s.

\subsection{Verbonde aan die kerk}

Die tweede uitdaging gaan verder as die eerste: die Sendingwetenskap het nie alleen 'n Christelike uitgangspunt nodig nie, maar dit kan ook nie in isolasie van die kerk funksioneer nie. Die sending en die Sendingwetenskap het die kerk nodig! In die sending gaan dit nie alleen om die missio Dei (God se sending in die wêreld nie), maar ook om die missio ecclesiae (die sending van die kerk). Die Sendingwetenskap moet die kerk op sy missionêre pad begelei, moet sensitief wees vir die behoeftes van die kerk op dié gebied. Die kerk het gemotiveerde en goed toegeruste sendelinge nodig en daarvoor moet daar binne die teologiese opleiding ruimte gemaak word. Maar die kerk het veral predikante met 'n sendingvisie nodig, manne en vroue wat die opbou van 'n missionêre gemeente as een van hul hoogste prioriteite aanvaar. Ook by die beplanning en begeleiding van die kerk se sendingtaak, plaaslik, sinodaal en wêreldwyd het die Sendingwetenskap 'n bydrae te lewer.

Aan die ander kant is dit egter net so waar dat die Sendingwetenskap van die kerk afhanklik is, dat die Sendingwetenskap kwalik sonder die insette wat van die kant van die kerk gemaak word, sonder die sendingervaring van die kerk, bowe-al sonder die korreksies wat vanuit die kerklike praktyk gemaak word, kan klaarkom. So min as wat 'n mediese fakulteit aan 'n universiteit sonder 'n hospitaal sy vak kan beoefen en studente kan oplei, so min kan 'n Sendingdepartement sonder die kerk funksioneer.

Onder "kerk", sou in die eerste plek die NG Kerk verstaan kan word. As deel van die Teologiese Fakulteit van die NG Kerk is dit immers hierdie departement se taak om, behalwe die akademiese beoefening van die vak Sendingwetenskap, die missionêre aksie van dié kerk dien. Tog moet die belange van die wyer kerklike gemeenskap, die NG Kerkfamilie, die Afrikaanse Susterskerke én die ander kerklike gemeenskappe in Suid-Afrika, ook aan die orde gestel word.

Dit is van ewe groot belang dat samewerking met die belangrike ekumeniese iiggame in ons land, sowel as met talle para-kerklike organisasies gesoek en gehandhaaf moet word. Ons het heelwat van ons gespreksgenote te leer - en vanuit ons eie Gereformeerde tradisie het ons hopelik ook 'n bydrae tot die gesprek te lewer. Sending en ekumene, het die geskiedenis ons geleer, gaan hand aan hand. Net só kan Sendingwetenskap nie anders as om ekumenies beoefen te word nie. 
Die Sendingwetenskap moet egter nie net op die kerke en organisasies in ons eie land fokus nie. Ons het die insig en ervaring van ons vennote in Europa en Amerika nodig. Wat ons selfs nog nodiger het, is die lesse wat die jonger dinamiese kerke uit die Derde Wêreld ons kan leer. Op pad na die jaar 2000 sal ons onsself gedurig daaraan moet herinner dat die swaartepunt van kerklike bedrywighede aan die verskuif is, van die noordelike na die suidelike halfrond. Aan die begin van die 20ste eeu, berig Walbert Bühlmann, het 85 persent van alle Christene in die Weste gewoon. Aan die begin van die 21 ste eeu sal 58 persent van alle Christene in Derde Wêreldlande leef! Die opkoms van die sogenaamde "Derde Kerk", sê Bühlmann, is waarskynlik die mees epog-makende kerklike gebeure van die laaste dekades van die 20 ste eeu ${ }^{6}$. Die vrae wat vanuit dié kerke aan die orde gestel word, die eiesoortige behoeftes wat hulle ontwikkel, die lesse wat uit hul ervaring geleer word, die suksesse wat hulle in hul dialoog met mense van ander godsdienste behaal, is van die sake wat die Sendingwetenskap op pad na die Derde Millennium nie durf ignoreer nie.

\subsection{Ons konteks: Afrika}

Die Sendingwetenskap is egter nie net op die kerk gerig nie, maar ook op die wêreld. Oral waar die kerk die wêreld in beweeg, oral waar grense oorskrei word, waar die "kerk as verrassing" sy verskyning maak, moet die Sendingwetenskap op sy pos wees. In 'n wêreld wat klein geword het, in 'n tyd van omwenteling en verandering op elke lewensterrein, stel dit moeilike maar ook hoogs interessante eise aan ons vakwetenskap. Hoe ernstiger die sending dié taak opneem, het David Bosch betoog, hoe duideliker sal hy ondervind dat daar 'n dubbele transformasieproses aan die gang is: enersyds word die wêreld deur die evangelieboodskap van Christus verander; maar andersyds word die sending deur die wêreld verander. Vandaar die titel van sy magnum opus: Transforming Mission, 'n titel wat op hierdie dubbele transformasieproses dui.

Bo alles sal ons moet onthou dat ons konteks dié van Afrika is. Een en dertig jaar gelede, tydens die stigtingsvergadering van die $\mathrm{S} A$ Werkgemeenskap vir Sendingwetenskap, het die doyen van NG missioloë, W J van der Merwe, 'n roerende pleidooi gelewer: neem Afrika ernstig op! Kyk wat in Afrika gebeur, bestudeer sy eiesoortige probleme, luister wat ander oor Afrika sê, bowenal, hoor wat mense uit Afrika self te sê het $^{7}$. J N J Kritzinger stel dit méér as duidelik. Prioriteit nommer een vir die sendingwetenskap - vir elke teologiese dissipline - is die Afrikaniseringsproses. Hy gaan voort: "We have no contribution to make to the 
worldwide debates in theology or religious studies, if we do not approach those debates from a position of being immersed in the context of this country and the continent of Africa. I am not advocating isolationism from the academic traditions of the North, but I am worried about the inability of our faculty as a whole to grapple with the realities of our African context" ${ }^{\prime 8}$. Wat Kritzinger sê moet met groot erns bejeën word. Vir ons leerplanne, ons navorsingstrategie, selfs vir die samestelling van ons toekomstige dosentekorps, hou die Afrikaniseringsproses geweldige uitdagings in.

Om dit te doen, om in ons akademiese arbeid nie maar net napraters van Europese en Amerikaanse teoloë te wees nie - soos Attie van Niekerk in sy veelbesproke boek Saam in $A f r i k a^{9}$ beskryf - is moeilik. Dit geld ook vir swart teoloë wat hul basiese opleiding in die Westerse tradisie ontvang het. John Mbiti, 'n baanbreker op dié gebied, vertel op humoristiese wyse van die dilemma van die die jong swart Doktor in Teologie wat na jare se studie in Duitsland, in sy tuisdorp in Wes-Afrika terugontvang word. Die hele gemeenskap was dié dag daar om hom te verwelkom. Meteens is daar 'n kommosie. Sy suster, 'n getroude vrou, het in 'n beswyming op die grond geval. Almal kyk na die geleerde man. Wat gaan hy doen?

Mbiti gaan voort: "Let's take her to the hospital", he calls urgently. They are stunned. He becomes quiet... Finally a schoolboy says: "Sir, the nearest hospital is 50 miles away, and there are few buses that go there". Someone else says: "She is possessed. Hospitals will not cure her!" The chief says to him: "You have been studying theology overseas for ten years. Now help your sister. She is troubled by the spirit of her great aunt". He looks around. Slowly he goes to get Bultmann, looks at the index, finds what he wants, reads again about spirit possession in the New Testament. Of course he gets the answer. Bultmann has demythologized it. $\mathrm{He}$ insists that his sister is not possessed. The people shout: "Help your sister, she is possessed!10".

Deur die jare het die Instituut vir Sendingkundige en Ekumeniese Navorsing (ISWEN) onder leiding van professor J J (Dons) Kritzinger, hierdie uitdaging aanvaar. 'n Hele reeks publikasies oor Afrika - sy godsdiens, sy swart pioniers, die kerke, die dilemmas en uitdagings, die teologie van dié kontinent - het reeds die lig gesien. Op dié pad moet voortgegaan word. Daarvoor is die hulp in insigte van kollegas van ander teologiese fakulteite en instansies onontbeerlik, by name dié van die S A Raad van Kerke, die All Africa Conference of Churches, die Association of Evangelicals in Africa en van die Ecumenical Association of Third World Theologians. 
Miskien nog die heel belangrikste: om Sendingwetenskap in Afrika te beoefen, beteken om nie net na predikante en teoloë te luister nie, maar om na die digters en storievertellers, die romanskrywers van Afrika te luister. Die werk van skilders en beeldhouers, die musiek wat in kerke én op straathoeke gehoor word, sal ons help om die hartklop van ons kontinent - waarop ons al só lank woon en nog so min verstaan - te hoor.

\section{4 'n Relevante agenda}

In die verlede het die Sendingwetenskap nogal daarin geslaag om die kerk op sy missionêre pad te begelei. Aan die begin van die eeu, toe rondom die Eerste groot wêreldsendingkongres te Edinburgh (1910), die optimisme hoog gevlam het, toe die marsbevel van die kerk "the evangelization of the world in this generation" was, was sendingwetenskaplikes op hul pos, om te help beplan, om te motiveer en toe te rus, om sendingmetodes te ontwerp. Toe die ingewikkeldheid van die sendingproses na vore gekom het, toe - veral na die Tweede Wêreldoorlog - allerlei twyfelvrae oor die legitimiteit van die sending, oor die presiese verhouding tussen die Christendom en die ander groot godsdienste na vore gekom het, toe die ontsettende sosio-ekonomiese, politieke, kulturele en ekologiese problematiek die aandag van die kerk en die sending opgeëis het, toe spanning tussen die "evangelicals" en "ecumenicals" die Protestantse sending getorpedeer het, het die Sendingwetenskap weer eens 'n bydrae gelewer.

Op dieselfde wyse sal die Sendingwetenskap, op pad na die Derde Millennium moet toesien dat sy agenda relevant bly.

In Rooms-Katolieke kringe word die afgelope tyd ernstige aandag aan die agenda van die kerk en sending wêreldwyd, maar veral ook in Afrika, gegee. Die verklaring Ecclesia in Africa, die vrug van vyf jaar se werk deur die Sinode van Biskoppe uit Afrika, wat deur Pous Johannes Paulus II tydens sy onlangse besoek aan ons land (September 1995) bekendgestel is, noem 'n hele aantal sake wat die ernstige aandag van die sending en die Sendingwetenskap in die jare wat kom, vra: beter opleiding, die kweek van inheemse leierskap, die sosio-ekonomiese getuienis van die kerk, die verhouding tussen die evangelie en kultuur - om slegs enkele sake te noem.

Wat die Protestantse wêreld betref sal met die ideale en behoeftes van die verskillende vertakkinge van die kerk, rekening gehou moet word. Die entoesiastiese evangeliese vleuel ("evangelicals") sal op hul pad begelei moet word - met eweveel entoesiasme, maar ook deur kritiese vrae op die agenda te plaas: Watter teologiese en hermeneutiese uitgangspunte word gebruik? Hoe hanteer hulle die Skrif? Hoe komprehensief - of ver- 
skraal - is hul sendingdefinisie? Hoe realisties is hul verwagtinge, hoe effektief hul metodes? Waaraan meet hulle hul "sukses"?

Eweneens sal die Sendingwetenskap die ekumeniese ("ecumenicals") vleuel moet bedien, ewe entoesiasties, sy dit dan ook krities. Aan die een kant sal die prioriteite van die "ecumenicals" - die groot projekte waartoe hulle hul vir die volgende dekades verbind het, projekte rondom eenheid, geregtigheid en vrede, armoede en ontwikkeling, rondom die ekologie, rondom minderheidsgroepe, die rol van vroue, rondom die evangelie en kultuur - hoog op die Sendingwetenskapagenda geplaas moet word. Andersyds sal die "ecumenicals" ook uitgedaag moet word oor hul Skrifgebruik en hermeneutiek, oor hul sendingdefinisie, om nie die vertikale dimensie van die evangelie uit die oog te verloor nie, om die geestelike nood van biljoene op aarde hul erns te maak.

As die beoefening van die Sendingwetenskap 'n bydrae kan lewer om die twee groepe nader aan mekaar bring, deur te om karikature af te breek, om "evangelicals" en "ecumenicals" op 'n punt te bring waar hulle mekaar se agendas aanvul en mekaar se eensydighede korrigeer, sal die hele kerklike gemeenskap gedien word.

Want uiteindelik wag daar op ons almal sáám die opperbelangrike vraag: wat moet die verhouding tussen die Christendom en die ander groot wêreldgodsdienste wees? Op dié punt het Katolieke en Protestante, "ecumenicals" en "evangelicals" mekaar dringend nodig. Die debat oor die getuienis aan en dialoog met mense van ander gelowe is lank nie meer iets wat tot studeerkamers en klaskamers - en afgeleë sendingposte - beperk is nie. Dis 'n saak wat die hele kerk, elke gemeentelid in ons land en talle studente aan ons universiteit, intens raak. Op ons almal wag daar 'n geestelike odyssee. Soos Odysseus en sy Argonaute sal Bybelwetenskaplikes, dogmatici, kerkhistorici, praktiese teoloë én ook sendingwetenskaplikes aan boord moet gaan, op 'n lang reis deur onbekende waters, na veraf strande. Op ons tog tussen die ander godsdienste deur, wag daar talle verrassings, nuwe insigte en dikwels ook gevare. Maar, skryf David Tracy, soos Odysseus sal ons uiteindelik terugkeer huis toe, na die bekende strande van ons geloof - sterker, wyser, sekerder van ons eie identiteit ${ }^{11}$.

\section{5 'n Verantwoordbare metodiek}

Die laaste uitdaging wat aan die orde gestel moet word is dié van 'n verantwoordbare, effektiewe metodiek by die beoefening en dosering van ons vak. Want dit is nie alleen belangrik dat 'n mens vra of Sendingwetenskap aan 'n teologiese fakulteit tuis hoort, of wat die inhoud van die vak en die uitdagings op sy agenda is nie. Uiteindelik moet die vraag na 
die hoe aan die orde gestel word. Die motto van die universiteit van Pretoria is "uitnemendheid". Dit pas ons derhalwe om ook wat die metodiek van ons vak betref, na dieselfde hoë doel te streef. Te midde van die lewendige debat oor wat universiteit-wees in ons dag beteken - oor hoe om aan die een kant nie hoë akademiese ideale te kompromitteer nie, en aan die ander kant 'n effektiewe diens aan 'n gemeenskap wat deur 'n tyd van drastiese verandering gaan, te lewer - sal die Departement Sendingwetenskap voortdurend oor sy eie bydrae moet besin.

In verskeie Derde Wêreldlande is sedert die sestiger jare baie oor dié onderwerp gepraat en geskryf. In Latyns-Amerika is verskillende pogings aangewend om die teologie uit sy veilige "kassie" aan 'n universiteit of seminarie te haal, om dit ná die massas te bring. Een metode was die sogenaamde TEE (Theological Education by Extension)-program, waardeur daar sedert die sestiger jare gepoog is om sou gou as moontlik, soveel as moontlik predikante en priesters plaaslik, waar hul werk en leef, op te lei. Paulo Freire het, met die verskyning van sy boek Pedagogy of the Oppressed 12 daarop gestaan dat opvoeders nie van bo af moet doseer asof hulle alle wysheid in pag het nie. Die dosent en die student moet op 'n interaktiewe manier tesame betrokke wees by 'n proses waarby altwee 'n bydrae lewer en waaruit altwee eweveel verryk word.

Binne die kring van plaaslike teoloë, ook sendingwetenskaplikes, is die saak net so druk bespreek. Die S A Raad van Kerke het die TEEprogram vir Suid-Afrikaanse omstandighede aangepas. Die Sweedse missioloog Sundkler, wat dikwels ons land besoek het, het gepleit dat Westerse "onderdele" sover as moontlik uit die masjinerie van teologiese opleiding in Afrika geweer moes word. Teologiese opleiding moes herdefinieer word, nie volgens die vereistes van die klassieke Westerse kurrikulum nie, maar in terme van wat die behoeftes van die kerk, die wêreld en die student, was ${ }^{13}$. Bongani Mazibuko, tot onlangs hoof van die Departement Sendingwetenskap aan die Universiteit van Durban-Westville, het eweneens sterk standpunte oor die saak gestel, soos ook Simon Maimela en Bonganjalo Goba ${ }^{14}$.

Dis egter nie alleen in Derde Wêreldlande dat 'n nuwe benadering ten opigte van teologiese opleiding nodig is nie. $\mathrm{Na}$ sy aanstelling as uitvoerende sekretaris van die Afdeling vir Ekumeniese Teologiese Opleiding van die Wêreldraad van Kerke in Geneve, het die Indonesiese teoloog Judo Poerwowidagdo tot die konklusie gekom dat ook die kerke in die Weste vernuwing op dié gebied dringend nodig het. As die kerke op pad na die jaar 2000 daarin wil slaag om 'n geloofwaardige getuienis die wêreld in te stuur, om die liggaam van Christus wêreldwyd op te bou en te 
versterk, sê Poerwowidagdo, sal ons die inhoud van ons kurrikulum en ons metodologie drasties moet verander. Daar sal in die jare wat voorlê aan 'n nuwe opleidingsmodel gewerk moet word, 'n model wat met enkele modifikasies ter wille van plaaslike omstandighede, wêreldwyd gebruik sal kan word. Al sou 'n mens nie alles wat hy in sy nuwe paradigma voorsien kon implementeer nie, pas dit ons in die Departement Sendingwetenskap (soos ook die ander teologiese dissiplines) om Poerwowidagdo se analise ernstig op te neem. Behou ten alle koste akademiese standaarde, pleit Poerwowidagdo, maar maak ook voorsiening vir die werklike behoeftes van die kerk en die plaaslike gemeenskap, lei nie net predikante op nie maar "leaders-enablers" wat die wyer gemeenskap kan dien, en sorg vir elektiewe, kontekstuele, ekumeniese kursusse wat die kritiese en innoverende vermoëns van die studente stimuleer.

\section{UITEINDELIK, DIE UITSPRAAK}

Ons het aan die einde van 'n lang wandeling deur die Sendingwetenskap gekom, deur die sale van die universiteit en die teologiese fakulteit waar die dissipline vir homself ' $n$ staanplek moes vestig, deur die kerk en die wêreld waar een uitdaging ná die ander op hom wag.

Maar nou moet ons terug na die hofsaal in Addis Abeba waar die Raad van Wyses gereed is om hul uitspraak te lewer. Was die sending - en ook die begeleidende Sendingwetenskap - die moeite werd? Hoe oordeel Afrika na al die eeue?

Die gryse ou regter Sinajina het sy keel skoongemaak en sy bril opgesit. Die joernaliste het hul penne oopgedraai. Die televisie-kameras het begin rol. In die hofsaal was dit doodstil toe hy die uitspraak begin voorlees:

"Die Raad van Wyses het eenstemmig besluit dat die oordeel oor die sending in Afrika vir eers uitgestel gaan word. Afrika sal nog 'n rukkie moet wag voordat die finale besluit geneem kan word. Die wag sal ons almal goed doen. En in die jaar 2000 sal ons met meer sekerheid kan sê of die sending ' $n$ bate of 'n verlies was. Dan sal ons kan besluit of die sending behoort voort te gaan of nie - en watter soort sending mag voortgaan. Dames en Here, die hofsitting is afgesluit".

Om Sendingwetenskap aan die einde van die eeuwending, by die aanbreek van die derde mileunium te beoefen, is 'n groot voorreg. Die uitdaging om die vak sinvol en relevant aan te bied, is inderdaad asemrowend, in die woorde van Van Engelen, "to link the always relevant Jesus event of twenty centuries ago to the future of the promised reign of God, for the sake of meaningful initiatives in the present"15. 
Om Sendingwetenskap te bedryf, het David Bosch geskryf, is 'n gevaarlike onderneming - alles wat gedoen en gesê word is stukwerk, broos en voorlopig. ' $n$ Mens kan eintlik net van Sendingwetenskap in konsepvorm praat. Missiologia semper reformanda est. Maar dis die enigste weg wat gevolg kan word, die weg waarlangs die Sendingwetenskap ook in die derde millennium nie alleen ancilla theologiae (die diensmaagd van die teologie) kan wees nie, maar ook ancilla Dei mundi (diensmaagd van God se wêreld) ${ }^{16}$.

Was en is dit die moeite werd? Die finale oordeel sal moet wag, tot die dag waarop die Groot Regbank vergader, wanneer nie die Wyse Manne van Afrika nie, maar die Koning van die Kerk self die finale uitspraak oor die kerk se sending - en Sendingwetenskap - sal lewer.

\section{NOTAS:}

$1 \quad J$ S Krüger, From one to many, Pretoria 1994, 16.

2 J N J Kritzinger, "Studying Religious Communities as Agents of Change", UNISA Public Lecture, Pretoria 1995, 6.

3 D J Bosch, $a w, 1991,9$.

4 J A B Jongeneel en J M van Engelen, "Contemporary Currents in Missiology" in: Missiology, an Ecumenical Introduction, Grand Rapids 1995, 456.

5 W R Shenk, Reflections on the modern Missionary Movement, Mission Studies Vol IX-1, 17 (1992), 42-78.

6 Walbert Bühlman, Courage, Church! Maryknoll 1978, 131.

7 W J van der Merwe, "Die beoefening van Sendingwetenskap in Afrika" in Sendingwetenskap vandag in Terreinverkenning (red D J Bosch), Pretoria 1968, 9-12.

$8 \quad \mathrm{~J}$ N J Kritzinger, $a w, 18$.

9 A S van Niekerk, Saam in Afrika, Kaapstad 1992, 84.

10 John S Mbiti, "Theological impotence and the university of the church" in: Mission Trends No 3 (red G H Anderson, T F Stransky), New York 1976, 6-8.

11 David Tracy, On Naming the Present. Reflextions on God, Hermeneutics and the Church, Maryknoll London 1994, 136-139.

12 Paulo Freire, Pedagogy of the Oppressed, Harmonds Worth 1970.

13 B Sundkler, The Christian Ministry in Southern Africa, London 1960, 256 vv.

14 B Mazibuko, Education in Mission/Mission in Education, Frankfurt-am-Main, 1987. Sien ook H L Pretorius, "Relevante Teologiese Opleiding in belang van 'n Missionêre Kerk", in: Sendinggenade (red J du Preez), Bloemfontein 1986, 242-246.

15 Aangehaal deur D J Bosch, $a w, 1991,498$.

16 D J Bosch, $a w, 1991,498$. 